\title{
Proposta de um curso virtual de estatística descritiva elementar sob a ótica de um designer instrucional em nível de extensão
}

\author{
Proposal for a virtual course in elementary \\ descriptive statistics from the perspective of an \\ instructional designer at the level of extension
}

\author{
Sérgio Ricardo Magalhães ${ }^{1}$, Rossano Gimenes ${ }^{2}$, Renata Mônica Silva Amaral ${ }^{3}$ \\ ${ }^{1}$ e 3 Universidade Vale do Rio Verde - UninCor, campus Betim \\ ${ }^{2}$ Universidade Federal de Itajubá - Unifei, campus Itajubá \\ ${ }^{1}$ sergio.magalhaes@unincor.edu.br, ${ }^{2}$ rossanodunifei.edu.br, \\ ${ }^{3}$ prof.renata.amaral@unincor.edu.br
}

\begin{abstract}
Resumo - O presente estudo tem como objetivo apresentar uma proposta de criação e implementação de um curso virtual de Estatística Elementar, intitulado Elementos de Estatística Descritiva, para o ambiente virtual TelEduc. Sob o ponto de vista de autoria e de Design Instrucional do curso, o projeto foi apresentado, buscando atender a pressupostos multidisciplinares que se fazem fundamentais a um curso de natureza virtual. Explorou-se o contexto em que o projeto do curso será realizado e, do mesmo modo, foram discutidos os dados especificos de design. Apresenta-se também neste trabalho uma análise crítica do curso, apontando vantagens e desvantagens, bem como, caminhos a serem trilhados na busca da melhoria do mesmo. Ao final do trabalho realizou-se uma reflexão sobre como tratar questões e práticas educacionais em ambientes virtuais, onde se propõe criar/desenvolver mecanismos que permitam a elaboração de cursos mais dinâmicos, destacando a importância da atuação do Design Instrucional.
\end{abstract}

Palavras-chave - Ead. Design Instrucional. TelEduc. Estatística.

Abstract - This study aimed to present a proposal for creation and implementation of a virtual course of Statistics Elementary, entitled Elements of Statistics Descriptive for the virtual environment TelEduc. From the point of view of copyright and instructional design of the course, the design of the course was presented, to meet the multidisciplinary assumptions that are fundamental to forming a virtual course of nature. The context in which the project was of course will be conducted fairly exploited, the same way that data for design, specific concerning the project were much discussed. It is also working in a critical analysis of that pointing out the advantages, disadvantages and paths to be trilhados in seeking to improve it. At the end of the work took place as a reflection on work practices and educational issues in virtual environments, which proposes to create / develop mechanisms for the development of courses more dynamic, highlighting the importance of the role of Instructional Design.

Keywords - Distance learning. Instructicional Design. TelEduc. Statistics.

\section{INTRODUÇÃO}

A educação a distância $(\mathrm{EaD})$ é um processo de ensino-aprendizagem, mediado por tecnologias, no qual professores e alunos estão separados espacial e/ou temporalmente.

Esta modalidade de ensino oferece comodidade aos agentes educacionais envolvidos, reduz custos e amplia as fronteiras da sala de aula, para além dos limites de espaço ou de tempo, facilitando a interação dos alunos e dos educadores. 
Neste contexto, o objetivo principal deste trabalho é apresentar um projeto de criação de um curso virtual, no ambiente TelEduc, modalidade de extensão, na área de estatística básica, intitulado Elementos de Estatística Descritiva.

Neste artigo buscou-se contemplar as metodologias e técnicas que devem ser consideradas e avaliadas na implantação de cursos virtuais, de acordo com a intervenção mediadora e integradora, multidisciplinar, proporcionada pelo profissional, especialista em Design Instrucional.

São apresentados dados gerais de um projeto instrucional, tais como: o contexto em que o projeto será realizado, o tema, os objetivos e o cronograma do curso, seus módulos e conteúdos. Além da definição do público alvo, há a explicitação do ambiente virtual, os tipos de mídias a serem adotados, os tipos de avaliação e prazos, as teorias pedagógicas que embasam o projeto, o tipo de comunicação e as definições das formas de interação e de feedback. Também são explicitados alguns recursos de design que foram desenvolvidos para o curso, destacados através do Mapa de Atividades e pelo Storyboard.

Ao final do artigo é apresentada uma análise do projeto, na qual se discutem os aspectos positivos, determinantes para o sucesso do curso.

\section{DESIGN INSTRUCIONAL DO CURSO}

\section{II.1 O AMBIENTE TELEDUC}

O ambiente virtual de aprendizagem escolhido é o TelEduc, que é um AVA, Ambiente de Aprendizagem Virtual, desenvolvido pelo Nied (Núcleo de Informática Aplicada à Educação) do Instituto de Computação da Unicamp (Universidade Estadual de Campinas), para a realização de cursos a distância por meio da Internet.
Sua escolha se justifica em função da facilidade de utilização dos recursos do ambiente de acordo com o perfil de seus usuários, que se dividem entre alunos e formadores.

Deste modo, o formador, ao montar um curso, irá escolher e selecionar o recurso que achar pertinente e apropriado para compor o ambiente que atenda seu público alvo. Os recursos disponíveis encontram-se no frame a seguir, visualizado na FIG. 1.

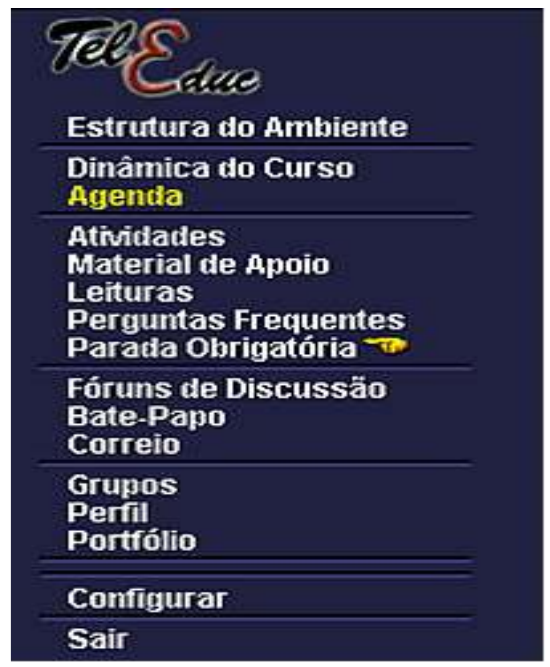

Figura 1 - Frame com os principais recursos do Teleduc

Os recursos do ambiente Teleduc, conforme discutido por Pedra (2008), apresentam as seguintes funcionalidades:

Estrutura do Ambiente: funcionamento do ambiente e dos cursos oferecidos.

Dinâmica do Curso: informações gerais sobre a metodologia e a organização do curso.

Agenda: página de entrada, contendo a programação do dia e a programação anterior.

Atividades: atividades propostas realizadas no decorrer do curso.

Material de apoio: informações relacionadas à temática do curso, subsidiando as atividades.

Leituras: publicação de artigos e referências de revistas, jornais, endereços na Web, etc.

Perguntas Frequentes: perguntas realizadas durante o curso e suas respectivas respostas. 
Parada

Obrigatória:

materiais problematizadores para desencadear reflexões e discussões.

Mural: espaço para publicação de informações, disponibilizado para todos os participantes.

Fóruns de Discussão: tópicos em discussão para participação dos alunos por meio de mensagens.

Bate-Papo: conversa de forma síncrona entre os alunos e os formadores.

Correio: correio eletrônico interno ao ambiente para que os participantes enviem e recebam mensagens.

Grupos: formação de grupos e publicação da produção realizada em arquivos no Portfólio.

Perfil: apresentação do sujeito, possibilitando a aproximação para a escolha de parceiros no desenvolvimento de atividades.

Diário de Bordo: propicia aos alunos a descrição da reflexão sobre seu processo de aprendizagem, que pode ser acompanhada pelo formador.

Portfólio: ferramenta para publicar arquivos e informações a serem utilizados ou desenvolvidos no curso. Pode ser particular ou compartilhado e possibilita a realização de comentários.

Acessos: acompanhamento da freqüência e do acesso dos usuários ao ambiente.

\section{II.2 TEORIAS PEDAGÓGICAS QUE EMBASAM O MODELO DE DESIGN}

As teorias pedagógicas que embasam o modelo de design adotado nesta proposta de curso são:

Construtivista: De acordo com Macedo (2004), trata-se de uma teoria baseada na construção do conhecimento através das interações do indivíduo com outros, com o meio ou da relação do novo conhecimento com a própria construção mental de significados. Segundo este autor, nesta teoria, aprender é uma interpretação do mundo, pois é um processo ativo no qual o significado é desenvolvido com base em experiências.

Cognitivista: Teoria baseada na construção do conhecimento onde a aprendizagem se faz de fora para dentro (GAUTHIER, 2005). Nesta teoria, a aprendizagem é um processo de armazenamento de informações, pelo qual ocorre a organização do conteúdo e de ideias a respeito de um assunto, em uma área particular de conhecimento.

\section{II.3 MíDIAS A SEREM UTILIZADAS}

As mídias planejadas para este curso são:

- Imagem Fixa: esquema, desenho;

- Imagem em movimento: animação.

\section{II.4 MÓDULOS DO CURSO}

QUADRO 1 - Módulos / Unidades, sub-unidades e seus objetivos do curso Elementos de Estatística Descritiva

\begin{tabular}{|c|c|c|c|}
\hline $\begin{array}{c}\text { Aula } \\
/ \\
\text { Sema } \\
\text { na }\end{array}$ & Unidade & Sub-unidades & Objetivos específicos \\
\hline $\begin{array}{c}\text { Aula } \\
1\end{array}$ & $\begin{array}{l}1 \text { Conceitos } \\
\text { básicos }\end{array}$ & $\begin{array}{l}\text { 1.1 Histórico, conceito, } \\
\text { campo de aplicação. } \\
\text { 1.2 Arredondamento de } \\
\text { dados. } \\
\text { 1.3 Coleta de dados. } \\
\text { 1.4 Tipos de Dados e } \\
\text { Variáveis }\end{array}$ & $\begin{array}{c}\text { - Identificar os tipos de } \\
\text { dados e suas } \\
\text { classificações } \\
\bullet \quad \text { Fazer o } \\
\text { arredondamento } \\
\text { adequado de dados }\end{array}$ \\
\hline $\begin{array}{c}\text { Aula } \\
2\end{array}$ & $\begin{array}{l}2 \text { Séries } \\
\text { estatísticas }\end{array}$ & $\begin{array}{l}\text { 2.1 Tipos de Séries } \\
\text { Estatísticas } \\
\text { 2.2 Tipos de gráficos }\end{array}$ & $\begin{array}{c}\text { - Identificar os tipos de } \\
\text { séries estatísticas } \\
\text { - Construir e interpretar } \\
\text { gráficos }\end{array}$ \\
\hline $\begin{array}{c}\text { Aula } \\
3\end{array}$ & $\begin{array}{c}3 \text { Medidas } \\
\text { de tendência } \\
\text { central }\end{array}$ & $\begin{array}{l}\text { 3.1 Médias } \\
\text { 3.2 Mediana } \\
\text { 3.3 Moda } \\
\text { 3.4 Separatrizes }\end{array}$ & $\begin{array}{c}\text { - Calcular as medidas de } \\
\text { tendência central } \\
\text { - Interpretar as medidas } \\
\text { de tendência central }\end{array}$ \\
\hline $\begin{array}{c}\text { Aula } \\
4\end{array}$ & $\begin{array}{l}4 \text { Medidas } \\
\text { de dispersão }\end{array}$ & $\begin{array}{l}\text { 4.1 Desvio médio } \\
\text { 4.2 Desvio padrão } \\
\text { 4.3 Variância } \\
\text { 4.4 Coeficiente de } \\
\text { variação }\end{array}$ & $\begin{array}{l}\text { - Calcular as medidas de } \\
\text { dispersão } \\
\text { - Interpretar as medidas } \\
\text { de dispersão }\end{array}$ \\
\hline $\begin{array}{c}\text { Aula } \\
5\end{array}$ & $\begin{array}{l}5 \text { Medidas } \\
\text { de } \\
\text { assimetria e } \\
\text { curtose }\end{array}$ & $\begin{array}{l}5.1 \text { Coeficiente de } \\
\text { assimetria } \\
5.2 \text { Coeficiente de } \\
\text { curtose }\end{array}$ & $\begin{array}{l}\text { - Determinar as medidas } \\
\text { de assimetria e curtose }\end{array}$ \\
\hline
\end{tabular}


O curso constará de cinco unidades, conforme o Quadro 1, que irão se entrelaçando ao longo do processo. Estas unidades não devem ser vistas como unidades estanques, pois cada uma se relaciona com as demais, na medida em que a complexidade das atividades se intensifica.

\section{II.5 ENCONTROS PRESENCIAIS}

A atividade final do curso constará de um encontro presencial de 3 horas-aulas a ser realizado no pólo do curso.

\section{II.6 OBRIGATORIEDADE DA REALIZAÇÃO DAS TAREFAS}

Todas as atividades propostas deverão ser realizadas, independentemente se será ou não avaliada.

A participação do aluno bem como o desenvolvimento das atividades de acordo com o cronograma proposto é de suma importância para o seu desempenho e a conclusão do curso.

\section{II.7 PRAZOS PARA EXECUÇão E/OU PARTICIPAÇÃO DE TAREFAS}

Para cada unidade serão disponibilizadas as agendas com as atividades que deverão ser desempenhadas. Cada atividade deverá ser realizada em no máximo três dias, para avaliação pelo tutor. Também os fóruns terão prazo máximo para participação de três dias.

\section{II.8 DINÂMICA DO CURSO}

\section{II.8.1 OBJeTIVOS DO CURSO}

Habilitar o aluno a:

- Identificar a base de dados, objeto da análise estatística.

- Calcular as medidas de tendência central e dispersão.

- Representar graficamente a base de dados.

- Aplicar os conceitos estudados em situações do dia a dia.

\section{II.8.2 PÚBLICO ALVO}

Estudantes e Graduados em todas as áreas.

\section{II.8.3 PRÉ-REQUISITOS}

- Acesso à internet;

- Dedicação de uma hora por dia para desenvolver as atividades do curso;

- Presença no encontro presencial.

\section{II.8.4 DURAÇÃO DO CURSO}

Aproximadamente 5 semanas.

$$
\text { II.8.5 AVALIAÇÃO }
$$

- Processual: participação dos alunos nas atividades sugeridas;

- Final: avaliação escrita sobre o conteúdo ministrado no curso.

\section{II.8.6 RESULTADOS ESPERADOS}

Ao final do curso espera-se que os participantes estejam familiarizados com os principais conceitos relacionados aos Elementos de Estatística Descritiva, bem como suas aplicações.

\section{II.8.7 CONTEÚDO}

O curso contém cinco unidades, listadas a seguir:

$11^{a}$ Unidade: Conceitos básicos

$\underline{2^{a} \text { Unidade: }}$ Séries estatísticas

$\underline{\mathbf{3}^{\text {a }} \text { Unidade: }}$ Medidas de tendência central

$4^{\text {a } \text { Unidade: }}$ Medidas de dispersão

$\underline{5^{a} \text { Unidade: }}$ Medidas de assimetria e curtose

\section{II.9 TIPOS DE COMUNICAÇÃO}

O tipo de linguagem adotado para este curso será a linguagem textual informal, cujo gênero, conforme Paiva (2001), é muito adequado ao contexto digital. 
Esta linguagem será cuidadosamente adaptada e revisada às características do tema a ser explorado, do público alvo e dos objetivos a serem alcançados. Outros recursos poderão ser utilizados, dependendo da necessidade de cada turma.

Para interação dos participantes serão agendados chats e programados fóruns de discussão em cada unidade do curso. O tutor será o mediador de todas as discussões.

\section{II.9.1 FORMAS DE INTERAÇÃO E FEEDBACK}

Para todas as unidades deste curso estão previstos chats e fóruns de discussão para interação dos alunos, tutores, formadores e convidados. O tutor dará os feedbacks à medida que as atividades forem realizadas ou quando solicitado pelo aluno.

$\mathrm{O}$ aluno terá papel ativo em todo o processo, construindo seu aprendizado e colaborando com a aprendizagem do grupo.

\section{II.9.2 RECURSOS DE DESIGN ESPECÍFICOS DO CURSO}

O desenvolvimento do projeto do curso proposto, Elementos de Estatística Descritiva, contará com recursos de design, construídos basicamente através de um conjunto detalhado de informações organizadas em dois diferentes documentos: Mapas de atividades e Storyboard.

Os Mapas de atividades consistem em um planejamento detalhado das atividades do curso, disponibilizadas em um Ambiente de Aprendizagem Virtual (AVA), conforme foi discutido por Barreto (2004). Segundo este autor, trata-se de um documento imprescindível para nortear o professor na elaboração de seu curso on-line.

O mapa de atividades bem elaborado detalha todas as informações necessárias para que o professor crie as atividades ou tarefas planejadas, diretamente nas ferramentas do ambiente de aprendizagem virtual. (BARRETO, 2004, p. 24).
O Quadro 2 apresenta um exemplo de mapa de atividades no qual estão apresentadas as atividades propostas para o curso, seguindo uma distribuição em unidades e subunidades, em concordância com o tema e objetivos específicos de cada aula/semana que se pretende atingir.

O Storyboard é um recurso gráfico muito utilizado pelos profissionais de publicidade. Este recurso também apresenta grande potencial para ser usado na educação, especialmente na EaD.

Do ponto de vista de Filatro (2008), um Storyboard bem elaborado serve como roteiro ao designer instrucional e é um poderoso recurso de comunicação para toda a equipe interdisciplinar.

O Storyboard é o esboço de um projeto multimídia destinado a ilustrar para toda a equipe de design e de desenvolvimento os recursos e as funcionalidades do produto final. O nível de detalhamento requerido para os Storyboards de um curso online depende do contexto no qual ele será produzido e implementado.. (FILATRO, 2008, p. 87).

Segundo Oliveira (2008), o detalhamento e roteiro dos Storyboards são manipulados por templates $^{l}$ que são formados basicamente por páginas e frames ${ }^{2}$.

Observando as figuras 2, 3 e 4, que se referem às aulas 1,2 e 3 , respectivamente, do curso, pode-se perceber como o conteúdo será apresentado e identificado por todos os participantes do curso.

Nos exemplos, os storyboards consistem de documentos que representam a forma como os conteúdos aparecerão no ecrã ${ }^{3}$, desde o texto até as diversas formas de interação e de navegação, correspondendo cada página do documento a um ecrã.

\footnotetext{
${ }^{1}$ Um template é um design de site que foi criado em um formato fácil para personalização, permitindo que qualquer pessoa possa construir um website de alta qualidade em questão de horas.

${ }^{2}$ Os frames são divisões da tela do browser em diversas.

${ }^{3}$ Tela ou superfície fluorescente sobre a qual se forma a imagem nos tubos catódicos (televisão, informática, etc.).
} 
QUADRO 2 - Mapa de Atividades do Curso Elementos de Estatística Descritiva

\begin{tabular}{|c|c|c|c|c|c|}
\hline $\begin{array}{c}\text { Aula/ } \\
\text { Semana } \\
\text { (período) }\end{array}$ & $\begin{array}{c}\text { Unidade } \\
\text { (Tema } \\
\text { principal) }\end{array}$ & $\begin{array}{c}\text { Sub-unidades } \\
\text { (Sub-temas) }\end{array}$ & Objetivos específicos & $\begin{array}{c}\text { Atividades teóricas e } \\
\text { recursos/ferramentas de } \\
\text { EaD }\end{array}$ & $\begin{array}{c}\text { Atividades práticas e } \\
\text { recursos/ferramentas de } \\
\text { EaD } \\
\end{array}$ \\
\hline $\begin{array}{l}\text { Aula } 1 \\
01 / 11 \\
07 / 11\end{array}$ & $\begin{array}{l}1 \text { Conceitos } \\
\text { básicos }\end{array}$ & $\begin{array}{c}\text { 1.1 Histórico, } \\
\text { conceito, campo de } \\
\text { aplicação. } \\
\text { 1.2 Arredondamento } \\
\text { de dados. } \\
\text { 1.3 Coleta de dados. } \\
\text { 1.4 Tipos de Dados e } \\
\text { Variáveis }\end{array}$ & $\begin{array}{l}1 \text { Identificar os tipos } \\
\text { de dados e suas } \\
\text { classificações } \\
2 \text { Fazer o } \\
\text { arredondamento } \\
\text { adequado de dados }\end{array}$ & $\begin{array}{c}\text { Atv } 1 \text { - Leitura do texto } \\
\text { "História da Estatística" } \\
\text { - Recurso: Livro digital } \\
\text { - Ferramenta Material de } \\
\text { Apoio } \\
\text { Atv } 2 \text { - Leitura do texto } \\
\text { "Tipos de Dados" - } \\
\text { Recurso: Livro digital - } \\
\text { Ferramenta Material de } \\
\text { Apoio } \\
\end{array}$ & $\begin{array}{l}\text { Atv } 3 \text { - Verificar o } \\
\text { entendimento sobre os } \\
\text { tipos de variáveis e suas } \\
\text { classifições (link - } \\
\text { Ferramenta Atividades) - } \\
\text { colocar os resultados na } \\
\text { ferramenta portfólio }\end{array}$ \\
\hline $\begin{array}{l}\text { Aula } 2 \\
\\
08 / 11 \\
15 / 11\end{array}$ & $\begin{array}{l}2 \text { Séries } \\
\text { estatísticas }\end{array}$ & $\begin{array}{c}\text { 2.1 Tipos de Séries } \\
\text { Estatísticas } \\
\text { 2.2 Tipos de gráficos }\end{array}$ & $\begin{array}{l}1 \text { Identificar os tipos } \\
\text { de séries estatísticas } \\
2 \text { Construir e } \\
\text { interpretar gráficos }\end{array}$ & $\begin{array}{c}\text { Atv } 4 \text { - Leitura do texto } \\
\text { "Séries Estatísticas e } \\
\text { Tipos de Gráficos" - } \\
\text { Recurso: Livro digital - } \\
\text { Ferramenta Material de } \\
\text { Apoio }\end{array}$ & $\begin{array}{c}\text { Atv } 5 \text { - Classificar os } \\
\text { tipos de séries estatísticas } \\
\text { (link - Ferramenta } \\
\text { Avaliações) } \\
\text { Atv 6- Construção de } \\
\text { gráficos (link - } \\
\text { Ferramenta Atividades) - } \\
\text { colocar os resultados na } \\
\text { ferramenta portfólio }\end{array}$ \\
\hline $\begin{array}{l}\text { Aula } 3 \\
15 / 11 \\
23 / 11\end{array}$ & $\begin{array}{c}3 \text { Medidas de } \\
\text { tendência } \\
\text { central }\end{array}$ & $\begin{array}{l}\text { 3.1 Médias } \\
\text { 3.2 Mediana } \\
\text { 3.3 Moda } \\
\text { 3.4 Separatrizes }\end{array}$ & $\begin{array}{l}1 \text { Calcular as medidas } \\
\text { de tendência central } \\
2 \text { Interpretar as } \\
\text { medidas de tendência } \\
\text { central }\end{array}$ & $\begin{array}{c}\text { Atv } 7 \text { - Leitura do texto } \\
\text { "Medidas de tendência } \\
\text { central" - Recurso: } \\
\text { Livro digital - } \\
\text { Ferramenta Material de } \\
\text { Apoio }\end{array}$ & $\begin{array}{c}\text { Atv 8- Cálculo das } \\
\text { medidas de tendência } \\
\text { central (link - Ferramenta } \\
\text { Atividades) - colocar os } \\
\text { resultados na ferramenta } \\
\text { portfólio } \\
\text { Atv 9- Aplicação das } \\
\text { medidas de tendência } \\
\text { central (link - Ferramenta } \\
\text { Avaliações) }\end{array}$ \\
\hline $\begin{array}{l}\text { Aula } 4 \\
23 / 11 \\
30 / 11\end{array}$ & $\begin{array}{l}4 \text { Medidas de } \\
\text { dispersão }\end{array}$ & $\begin{array}{l}\text { 4.1 Desvio médio } \\
\text { 4.2 Desvio padrão } \\
\text { 4.3 Variância } \\
\text { 4.4 Coeficiente de } \\
\text { variação }\end{array}$ & $\begin{array}{l}1 \text { Calcular as medidas } \\
\text { de dispersão } \\
2 \text { Interpretar as } \\
\text { medidas de dispersão }\end{array}$ & $\begin{array}{c}\text { Atv } 10 \text { - Leitura do texto } \\
\text { "Medidas de dispersão" } \\
\text { - Recurso: Livro digital } \\
\text { - Ferramenta Material de } \\
\text { Apoio }\end{array}$ & $\begin{array}{l}\text { Atv 11- Cálculo das } \\
\text { medidas de dispersão } \\
\text { (link - Ferramenta } \\
\text { Atividades) - colocar os } \\
\text { resultados na ferramenta } \\
\text { portfólio } \\
\text { Atv 12- Aplicação das } \\
\text { medidas de dispersão } \\
\text { (link - Ferramenta } \\
\text { Avaliações) }\end{array}$ \\
\hline $\begin{array}{l}\text { Aula } 5 \\
01 / 12 \\
07 / 12\end{array}$ & $\begin{array}{l}5 \text { Medidas de } \\
\text { assimetria e } \\
\text { curtose }\end{array}$ & $\begin{array}{l}\text { 5.1 Coeficiente de } \\
\text { assimetria } \\
\text { 5.2 Coeficiente de } \\
\text { curtose }\end{array}$ & $\begin{array}{c}1 \text { Determinar as } \\
\text { medidas de assimetria } \\
\text { e curtose }\end{array}$ & $\begin{array}{c}\text { Atv 13 - Leitura do texto } \\
\text { "Medidas de assimetria e } \\
\text { curtose" - Recurso: } \\
\text { Livro digital - } \\
\text { Ferramenta Material de } \\
\text { Apoio }\end{array}$ & $\begin{array}{l}\text { Atv 14- Cálculo das } \\
\text { medidas de assimetria e } \\
\text { curtose (link - } \\
\text { Ferramenta Atividades) - } \\
\text { colocar os resultados na } \\
\text { ferramenta portfólio. }\end{array}$ \\
\hline
\end{tabular}

\begin{tabular}{|l|l|l|} 
ISSN: 1984-3151 & www.unibh.br/revistas/exacta/ & V. 3 N. ${ }^{\circ} 1$ (2010) \\
\hline
\end{tabular} 
Título: Elementos de Estatística Descritiva

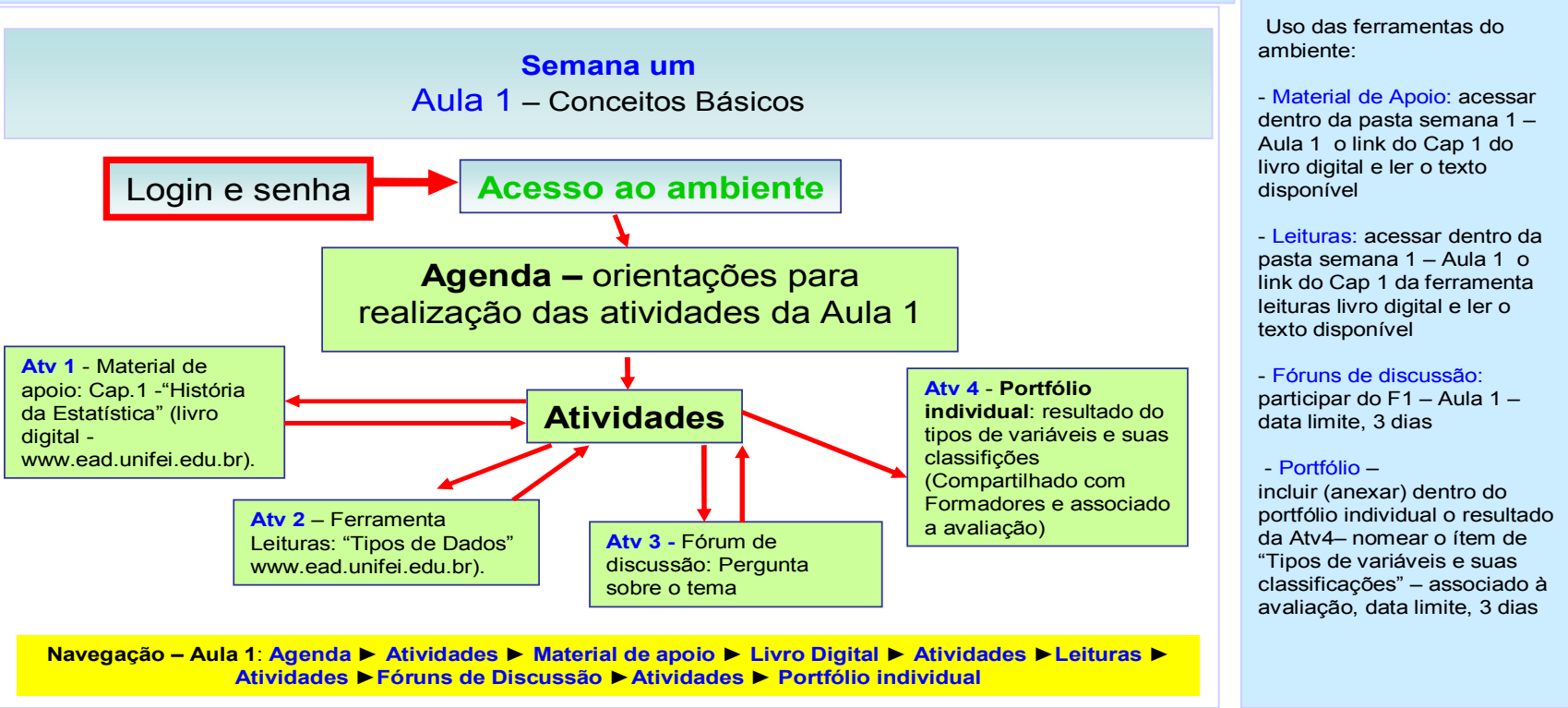

FIGURA 2-Storyboard referente à Aula 1 do curso Elementos de Estatística Descritiva

Título: Elementos de Estatística Descritiva Designer Instrucional: Sérgio Ricardo Magalhães $\quad N^{\circ}$ da tela: $02 \quad$ Data: 08/11/2008

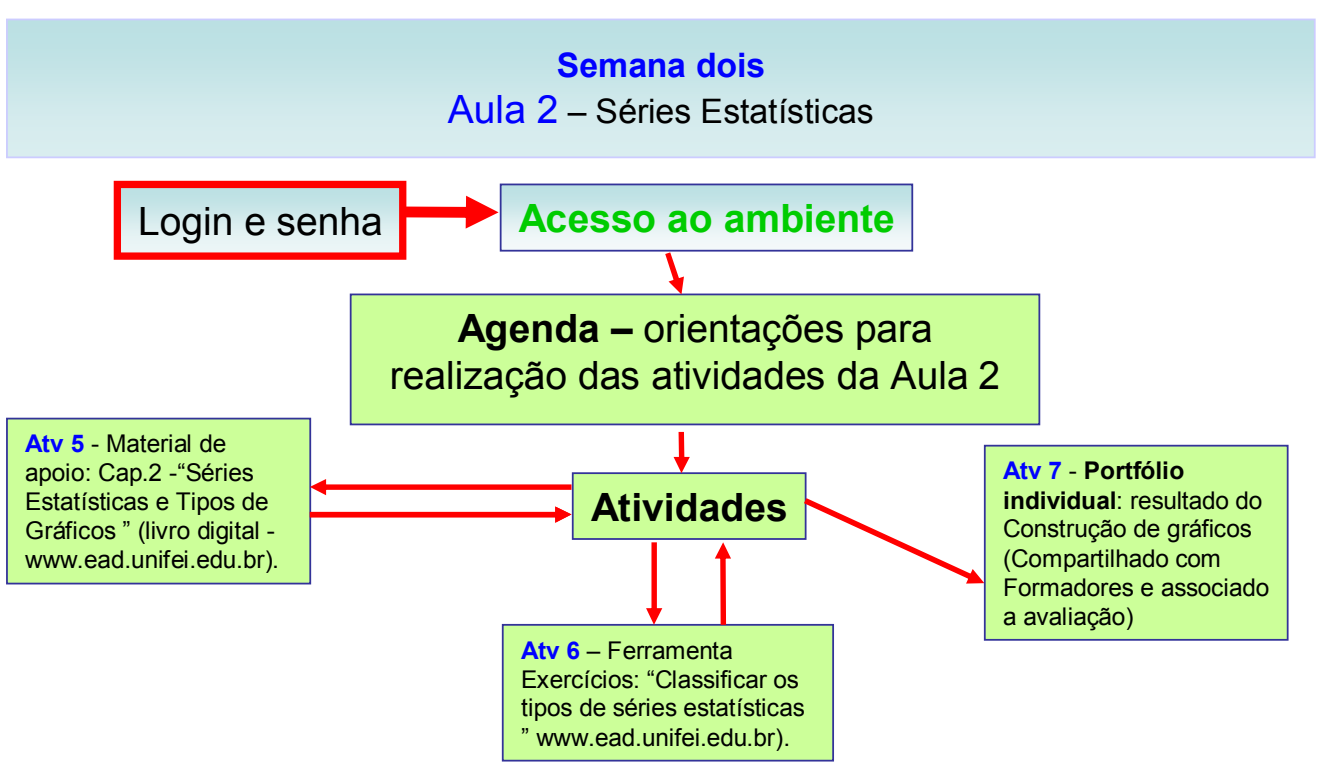

Navegação - Aula 2: Agenda $>$ Atividades $\$ Material de apoio $\$ Livro Digital $\$ Atividades $\$ Exercícios Atividades Portfólio individual
Informações para a equipe produção

Uso das ferramentas do ambiente:

- Material de Apoio: acessar dentro da pasta semana 2 Aula 2 o link do Cap 2 do livro digital e ler o texto disponível

- Exercícios: Resolver as questões propostas. A avaliação será automática com data limite para a resolução de 3 dias após a disponibilização.

- Portfólio -

incluir (anexar) dentro do portfólio individual o resultado da Atv7-nomear o ítem de "Construção de gráficos" associado à avaliação, data limite, 3 dias

FIGURA 3 - Storyboard referente à Aula 2 do curso Elementos de Estatística Descritiva

\begin{tabular}{l|l|l|} 
ISSN: 1984-3151 & www.unibh.br/revistas/exacta/ & V. 3 N. ${ }^{0} 1(2010)$ \\
\hline
\end{tabular} 
Título: Elementos de Estatística Descritiva

Designer Instrucional: Sérgio Ricardo Magalhães

$N^{\circ}$ da tela: 03

Data: $15 / 11 / 2008$

Semana três

Aula 3 - Medidas de Tendência Central

Navegação - Aula 3: Agenda $>$ Atividades $>$ Material de apoio $>$ Livro Digital $>$ Atividades $>$ Portfólio individual $>$ Atividades $>$ Portfólio individual

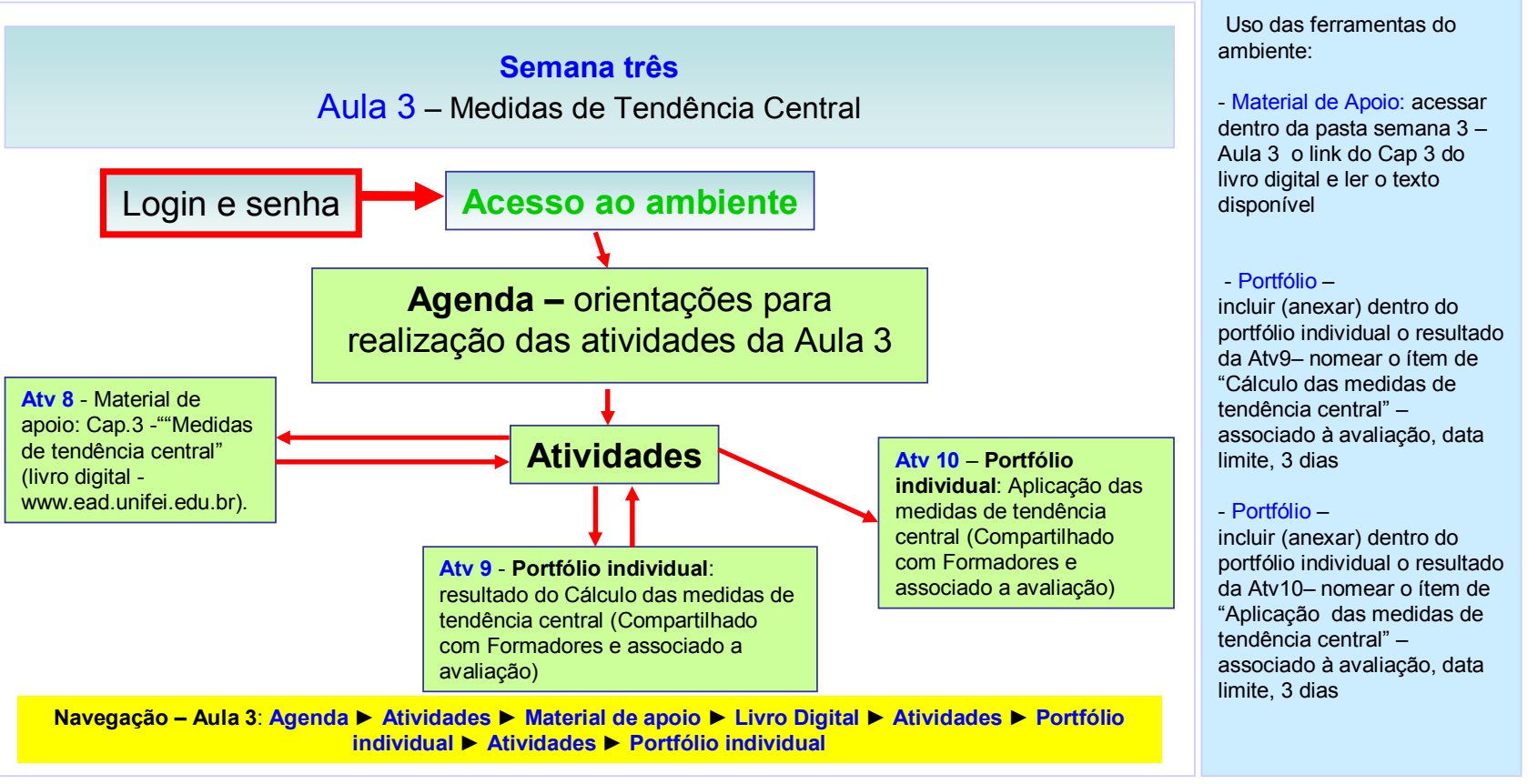

FIGURA 4 - Storyboard referente à Aula 3 do curso Elementos de Estatística Descritiva

\section{ANÁLISE Do PROJETO DE DESIGN INSTRUCIONAL}

O curso de extensão proposto, Elementos de Estatística Descritiva, destaca-se pela sua objetividade. Característica esta, que pode ser evidenciada na distribuição dos conteúdos que normalmente, em cursos regulares de graduação, são distribuídos nas disciplinas de Estatística I, em cargas-horárias que oscilam entre 60 e 72 horas semestrais e que neste estarão sendo oferecidos em 18 horas.

Todavia, seu grande diferencial está alicerçado nas teorias pedagógicas nas quais o curso foi idealizado. Ao contrário de cursos presenciais que simplesmente apresentam os conteúdos aos alunos, nossa proposta permite aos participantes, a construção dos conteúdos no decorrer do processo, que é intermediado por interações entre todos os envolvidos no curso.

Neste projeto de curso, procurou-se atender à teoria construtivista, na qual, segundo Mills (2002), os conteúdos são assimilados pelos alunos, depois deles terem construído o seu próprio significado.

Esta construção será gradativamente elaborada de modo que os participantes assimilem todos os conteúdos, sendo que em muitos momentos, sequer perceberão a evolução do nível de dificuldade do curso. Neste contexto, o professor assumirá o papel de facilitador, que conduzirá a interação e a discussão dos conteúdos durante todo o processo de ensino-aprendizagem.

Através de um ambiente colaborativo, as diversas atividades do curso serão suportadas computacionalmente através do

ISSN: 1984-3151

www.unibh.br/revistas/exacta/

V. 3 N. ${ }^{\circ} 1$ (2010) 
ambiente virtual TelEduc. Este ambiente é denotado pelo favorecimento da construção do conhecimento promovida pela integração de um conjunto de ferramentas, que possibilitarão um melhor desempenho de todos os envolvidos no processo ensinoaprendizagem do curso.

Deve-se salientar, que este AVA foi escolhido por permitir que a integração com os membros do curso, ocorra através de mecanismos/ferramentas tradicionais de comunicação mediada por computador, como o correio eletrônico, os fóruns de discussão e chats, que naturalmente já estão integradas ao ambiente. Para tornar estes espaços mais afetivos será adotada uma linguagem informal, o que facilita e promove o fluxo de informações entre os participantes.

Sob o ponto vista instrucional, percebe-se que o curso foi desenvolvido atendendo aos preceitos pedagógicos, que orientam o processo educacional de um curso desta modalidade de ensino, visando atender às necessidades do público alvo. Este fato pode ser nitidamente observado e evidenciado após a análise do Mapa de Atividades e do Storyboard.

Todos os cinco módulos/aulas do curso foram estruturados em materiais instrucionais, essencialmente textuais, que poderão ter recursos visuais ou outras mídias incorporados, à medida que se tornarem adequadas ao contexto do conteúdo abordado. Seria bastante pertinente, por exemplo, se a cada início de módulo/aula houvesse a inclusão de um vídeo explicitando o teor dos temas das unidades e subunidades do módulo, os objetivos destacados no Mapa de Atividades, além do que se espera que cada aluno apreenda ao final do estudo do módulo.

Deve-se considerar que a inclusão de recursos gráficos/visuais, conforme discutido por Souza (1999), são extremamente importantes num processo de educação a distância. Segundo este autor, a incorporação de figuras e animações gráficas, autoinstrutivas tem por finalidade contribuir efetivamente no processo de ensinoapredizagem.

Este aspecto tem total influência no ensino de estatística, já que podem ser utilizados recursos gráficos para mostrar comportamentos numéricos e ilustrar a teoria de erros envolvida, de modo a trazer ao aluno práticas estatísticas do dia-dia, auxiliando na interpretação dos dados coletados, e também na demonstração de técnicas de amostragem.

Outro aspecto que se deve ressaltar, confere à abrangência do público alvo. Como foi caracterizado a priori, o público alvo é constituído por estudantes ou graduados de qualquer área do conhecimento, residentes em diversas localidades, desde que possam comparecer ao encontro presencial. Isso ocorre pelos seguintes motivos:

1. Os alunos recém-chegados à graduação, normalmente cursam a disciplina de Estatística I, no primeiro período dos variados cursos de graduação, ficando quase sempre resistentes à assimilação dos conteúdos desta disciplina, em função das várias lacunas de saberes matemáticos que trazem do ensino médio. Assim, o curso de Elementos de Estatística Descritiva poderia atuar como um reforço, principalmente para aqueles que estão repetindo a disciplina.

2. Muitos alunos, na disciplina de Estatística II, oferecida normalmente, no segundo período, quando estão estudando conceitos de estatística inferencial, percebem a necessidade de retomar alguns conceitos básicos da Estatística I, que embora cursada tão próxima, foram esquecidos.

\begin{tabular}{l|l|l|} 
ISSN: 1984-3151 & www.unibh.br/revistas/exacta/ & V. 3 N.o 1 (2010)
\end{tabular} 
3. Outra parcela extremante significativa desta demanda, é constituída por alunos da especialização, mestrado e do doutorado, que sentem uma grande necessidade da retomada de conceitos básicos de Estatística Descritiva, para que consigam caminhar nos seus estudos, uma vez que o entendimento de artigos científicos e a condução de experimentos requerem tais pressupostos estatísticos.

Os riscos de implementação são mínimos. Para racionalizar possíveis custos de implantação, o curso foi pensado, objetivando utilizar a estrutura tecnológica já existente gratuitamente.

Com relação à recepção do curso, esta ficará por conta do aluno, que será encarregado de criar as condições de desenvolver as atividades propostas.

Os riscos de obsolescência do curso são pequenos. No aspecto tecnológico, embora a relativa rapidez com que equipamentos computacionais tornam-se obsoletos, isto não afetaria a oferta do curso, visto suas demandas mínimas de recursos computacionais.

No aspecto do conteúdo, os tópicos relacionados aos elementos de estatística, jamais estarão desatualizados. O que pode e deve ocorrer, são melhorias e implementações na metodologia dos conteúdos do curso.

\section{CONSIDERAÇÕES FINAIS}

Após a confecção deste trabalho que retrata o começo de um grande aprendizado, pode-se evidenciar que os modelos de cursos para educação a distância, possuem vários componentes que são aplicáveis a diversos cursos em todos os níveis de ensino.

Do ponto de vista cognitivo, o curso foi pensado de modo a unir diversas teorias, procurando promover, de forma eficaz e acessível, o ensino dos elementos de Estatística Descritiva, rompendo as barreiras impostas pelo ensino tradicional de ciências exatas.

Procurou-se priorizar através de estratégias e ferramentas variadas, que podem ser utilizadas em EaD, o aprofundamento dos saberes específicos propostos pelo curso, extremamente importantes para 0 desenvolvimento intelectual. Buscou-se, também, apresentar de modo contextualizado a aplicação destes saberes, mostrando o quão importante é a estatística para o desenvolvimento das ciências, bem como sua relação com o cotidiano.

Muitos modelos são propostos por diferentes pesquisadores. Há os que enfatizam estratégias tecnológicas, outros priorizam estratégias pedagógicas, além dos que buscam o entendimento da organização educacional em que o curso será implantado.

Procurou-se propor um modelo inicial de curso, que possibilitasse o gerenciamento de algumas questões específicas de $\mathrm{EaD}$ para que o mesmo fosse executável. E também, a intenção foi a de desenvolver um curso de curta duração, que possibilitasse uma visão sistêmica do mesmo, através da qual, se pudesse realizar todas as tarefas relacionadas ao curso, desde o planejamento, preparação do conteúdo, interação com os alunos, e o uso de recursos tecnológicos.

Assim, com a aliança do uso da tecnologia para a educação a distância, acredita-se na possibilidade de mudanças de paradigmas na qual o professor não seria o único responsável pelo planejamento e desenvolvimento de um curso. Pois, independente da proposta pedagógica, tornase fundamental, a participação dos vários atores de uma equipe multidisciplinar, que

\begin{tabular}{l|l|l|} 
ISSN: $1984-3151$ & www.unibh.br/revistas/exacta/ & V. 3 N.o 1 (2010) \\
\hline
\end{tabular} 
devem executar de forma integrada, tarefas segundo suas habilidades e competências, evitando cursos mal planejados.

Deste modo, ressalta-se a importância do design instrucional para a EaD virtual, cuja área de atuação deve ser pautada nos questionamentos científicos, para que sob influência de teorias cognitivas, possam ser desenvolvidas bases sólidas de conhecimentos que norteiem novas práticas educacionais.

\section{AgRAdECIMENTOS}

Os autores agradecem ao Centro Universitário de Belo Horizonte - UNI-BH por criar a oportunidade de publicação deste estudo.

\section{REFERÊNCIAS}

BARRETO, R. G. (org.). Tecnologias educacionais e educação a distância. Rio de Janeiro: Quartet, 2004.

FILATRO, A. Design Instrucional na prática. São Paulo: Prentice-Hall, 2008.

FRANCO, L.; BENFATTI, E.; BRAGA, D. Aplicando a ludopedagogia na engenharia através de dinâmicas colaborativas da educação virtual. Biblioteca Virtual da Educação a Distância da Universidade Federal de Itajubá, 2005.

GAUTHIER, C. Por uma teoria de pedagogia. Unijuí: Editora Unijuí, 2005.

MACEDO, L. Ensaios Construtivistas. 5 ed. São Paulo : Casa do Psicólogo, 2004.
MORENO, R. O. M. O desafio do planejamento ... e e o uso de Templates. Disponível em: < http://www.pr.gov.br/ batebyte/edicoes/1995/bb45/desafio.htm $>$.

Acesso em: 10 jul. 2009.

MILLS, J.; PLATTS, K.; BOURNE, M.; RICHARDS, H. Competing through competences. Cambridge: Cambridge University Press, 2002.

MORISSON, J. Designing Effective Intruction. 4. ${ }^{\mathrm{a}}$ ed. USA: John Wiley, 2004.

OLIVEIRA, M. E.. EaD na Escola. Livro Digital do Curso de Especialização em Desing Instrucional para EaD Virtual, 2008. < http://www.ead.unifei.edu.br/index.php?...id... >. Acesso em: 28 jul. 2009.

PAIVA, V. L. M. (org.). Interação e aprendizagem em Ambiente Virtual. Belo Horizonte, FALEUFMG, 2001.

PEDRA, G. S. Estrutura do ambiente Teleduc. Disponível em: < http://br.geocities.com/guilhermesilvaped/cur so online/tutorial teleduc.htm $>$. Acesso em: 12 jul. 2009.

SOUZA, A. C. Considerações metodológicas sobre a elaboração de cursos de ensino a distância: um exemplo de um curso de CAD suportado pela internet. 1999. 186 p. Dissertação (Mestrado em Engenharia de Produção) - Instituto de Engenharia, Universidade Federal de Santa Catarina, 1999.

\begin{tabular}{l|l|l|} 
ISSN: 1984-3151 & www.unibh.br/revistas/exacta/ & V. 3 N.o 1 (2010)
\end{tabular}

